\title{
Impact of an Herbal Dietary Supplement Containing Spilanthes acmella and Orchis latifolia on Testosterone in Young Men
}

\author{
Ryan G. Moran, Alex T. VonSchulze \& Richard J. Bloomer (Corresponding Author) \\ Cardiorespiratory/Metabolic Laboratory \\ School of Health Studies, University of Memphis, Memphis, TN, USA \\ E-mail: rbloomer@memphis.edu
}

Received: June 9, 2016 Accepted: August 28, 2016 Published: November 25, 2016

doi:10.5296/jbls.v8i1.10356 URL: http://dx.doi.org/10.5296/jbls.v8i1.10356

\begin{abstract}
Attention has been given recently to herbal dietary supplements proposed to elevate testosterone and nitric oxide. This study evaluated the impact of a supplement containing Spilanthes acmella extract and Orchis latifolia extract on total blood testosterone, cortisol, and nitrate/nitrite in healthy men. Methods: Thirteen men (25.0 \pm 1.0 years) were randomly assigned (double-blind, cross-over design) to ingest a supplement (containing Spilanthes acmella extract and Orchis latifolia extract) and a placebo daily for 14 days, with a 14-day washout period between assignments. Fasting blood samples were collected on the mornings of days 1, 4, 8, and 15 and analyzed for testosterone, cortisol, and nitrate/nitrite. On day 15, subjects ingested an acute dose of the supplement or placebo and blood was collected every 30 minutes for three hours, and analyzed for testosterone. Results: No increase of significance was noted for any biochemical variable $(p>0.05)$. However, a mean increase in testosterone from day 1 to day 15 of $29 \%$ was observed for the 13 subjects when ingesting the supplement, with a mean increase of $56 \%$ noted when only considering the 8 subjects who "responded" to treatment. Cortisol was increased approximately $19 \%$ when subjects ingested the supplement, compared to only $9 \%$ with the placebo. Conclusion: Two weeks of supplementation with an herbal preparation containing Spilanthes acmella extract and Orchis latifolia extract can increase testosterone in selected young men. The supplement also results in a moderate increase in cortisol. Larger scale studies are needed to further evaluate the impact of this herbal combination on testosterone in men.
\end{abstract}

Keywords: Spilanthes acmella, Orchis latifolia, dietary supplements, testosterone, nitrate 


\section{Introduction}

Currently, there exists a great deal of interest centered on the use of herbal-based dietary supplements to support certain aspects of human health (Egan, Hodgkins, Shepherd, Timotijevic, \& Raats, 2011; Nicoletti, 2012; Raskin et al., 2002). Of particular interest is the use of such supplements to increase circulating testosterone (Gunnels \& Bloomer, 2014) and nitric oxide (NO) (Achike \& Kwan, 2003; Zand, Lanza, Garg, \& Bryan, 2011) in men. Testosterone is the primary male sex hormone, impacting multiple physiological processes which can directly influence quality of life in men (Laaksonen et al., 2004; Laughlin, Barrett-Connor, \& Bergstrom, 2008; Shores, Matsumoto, Sloan, \& Kivlahan, 2006; Srinivas-Shankar et al., 2010; Tsujimura, 2013) (e.g. muscle strength, body composition, libido, mood). NO is an important signaling molecule known to promote vasodilation (Clements, Lee, \& Bloomer, 2014; Kellogg, Crandall, Liu, Charkoudian, \& Johnson, 1998), with the potential to favorably impact blood flow at rest and during exercise (Bond, Morton, \& Braakhuis, 2012; Crecelius, Kirby, Voyles, \& Dinenno, 2011; Kelly, Vanhatalo, Wilkerson, Wylie, \& Jones, 2013). While certain lifestyle factors such as regular exercise and dietary intake can favorably influence both circulating testosterone (Anderson et al., 1987; Arazi, Damirchi, Faraji, \& Rahimi, 2012; Kraemer et al., 1992; Linnamo, Pakarinen, Komi, Kraemer, \& Hakkinen, 2005; Nicklas et al., 1995; Reed, Cheng, Simmonds, Richmond, \& James, 1987; Travison, Araujo, Kupelian, O’Donnell, \& McKinlay, 2007) and NO (Bode-Boger, Boger, Schroder, \& Frolich, 1994; Hsieh, Juan, Darzynkiewicz, \& Wu, 1999; Koller, Huang, Sun, \& Kaley, 1995; Lima et al., 2014; Medina-Remón et al., 2015; Tanaka et al., 2015; White, 1975), selected herbal agents may provide additional benefit (Gunnels \& Bloomer, 2014).

Two plant-based nutrients that have received attention are Spilanthes acmella and Orchis latifolia. Both of these ingredients have been used in Ayurvedic medicine for several years, with multiple proposed physiological benefits (Bulpitt, Li, Bulpitt, \& Wang, 2007; Dubey, Maity, Singh, Saraf, \& Saha, 2013), including increased testosterone. Data examining the effects of botanical treatments in rats shows a dose dependent increase in serum testosterone levels when the animals are treated with Spilanthes acmella $(150 \mathrm{mg} / \mathrm{kg})($ Sharma et al., 2011) or Orchis latifolia $(200 \mathrm{mg} / \mathrm{kg}$ ) extracts (Bhargava, Thakur, Patil, \& Dixit, 2009). Orchis latifolia has also been noted to increase NO levels in rats treated at doses of $200 \mathrm{mg} / \mathrm{kg}$. Although animal data are available with regards to both Spilanthes acmella (Sharma et al., 2011; Wongsawatkul et al., 2008) and Orchis latifolia (Thakur \& Dixit, 2008), as well as anecdotal reports of enhanced health outcomes in human subjects using these agents, we are unaware of published human studies using these ingredients.

In the present pilot investigation, we used a randomized, placebo-controlled, cross-over design to determine the impact of short-term (14-day) supplementation of Spilanthes acmella and Orchis latifolia on blood testosterone, cortisol, and NO metabolites (nitrate/nitrite). We also included an acute experiment in which subjects received a single serving of the dietary supplement and had blood samples collected before and during a three-hour post ingestion period, in an attempt to determine the impact of acute ingestion of the supplement on blood testosterone levels. 


\section{MlMacrothink}

\section{Methods}

\subsection{Subjects}

Thirteen healthy men $(25.0 \pm 1.0$ years $)$ participated in this study. Subjects were physically active, with all subjects participating in a program of structured exercise (e.g. running, resistance training). The mean exercise training volume and history of our subjects, as well as physical characteristics, is presented in Table 1. Subjects were non-smokers with no known cardiovascular or metabolic diseases. Subjects were not using medications or dietary supplements thought to impact our chosen outcome measures. Subjects were allowed to continue use of dietary supplements that were not thought to impact our outcome measures (e.g. multi-vitamin, protein powder), but were required to maintain the same regimen throughout the entire study period. Subjects were not obese based on body mass index standards $\left(<30 \mathrm{~kg} \cdot \mathrm{m}^{-2}\right)$, as obese individuals often present with low testosterone values $(\mathrm{Ng}$ Tang Fui et al., 2013; Schneider, Kirschner, Berkowitz, \& Ertel, 1979). In addition, subjects did not have diagnosed depression or a history of sleep disorders, as both conditions are known to negatively impact testosterone concentration (Amatruda, Harman, Pourmotabbed, \& Lockwoodf, 1978; Andersen, Martins, D'Almeida, Bignotto, \& Tufik, 2005; Andersen \& Tufik, 2008; Carnahan \& Perry, 2004; Cortes-Gallegos et al., 1983; Doering et al., 1975; Markianos, Tripodianakis, Sarantidis, \& Hatzimanolis, 2007; Seidman et al., 2002). Recruitment of subjects took place at The University of Memphis via flyers, e-mail, and word of mouth. Subjects were informed of all procedures, potential risks, and benefits associated with the study through both verbal and written form. The study procedures were approved by the University Institutional Review Board (IRB) for Human Subjects Research (protocol \#3381) and subjects provided written informed consent. Subjects were compensated \$200 for their full participation.

Table 1. Characteristics of 13 men

\begin{tabular}{lc}
\hline Variable & Value \\
\cline { 2 - 2 } Age $(\mathrm{yrs})$ & $25.0 \pm 1.0$ \\
Height $(\mathrm{cm})$ & $177.2 \pm 2.1$ \\
Weight $(\mathrm{kg})$ & $84.4 \pm 4.0$ \\
BMI $\left(\mathrm{kg} \cdot \mathrm{m}^{-2}\right)$ & $26.8 \pm 1.0$ \\
Waist $(\mathrm{cm})$ & $86.1 \pm 2.4$ \\
Hip $(\mathrm{cm})$ & $101.1 \pm 1.9$ \\
Waist:Hip & $0.85 \pm 0.0$ \\
Body fat (\%) & $16.7 \pm 1.6$ \\
Heart rate (bpm) & $61.6 \pm 1.9$ \\
Systolic blood pressure (mm Hg) & $120.5 \pm 1.3$ \\
Diastolic blood pressure (mm Hg) & $77.9 \pm 1.5$ \\
Years anaerobic exercise training & $6.8 \pm 1.5$ \\
Hours per week anaerobic exercise & $3.4 \pm 0.6$ \\
Years aerobic exercise training & $7.9 \pm 1.6$ \\
Hours per week aerobic exercise & $4.0 \pm 1.8$ \\
\hline
\end{tabular}

Data are mean \pm SEM. 


\subsection{Initial Laboratory Visit: Screening Visit}

During the initial visit to the laboratory, subjects completed the informed consent form, health history, and physical activity questionnaires. Subjects' heart rate and blood pressure, height, weight, waist, and hip circumference were measured. Body composition was determined via dual energy x-ray absorptiometry (DXA) using a Hologic system (Discovery QDR series, Hologic Inc., Bedford, MA). Upon completion of screening, subjects were scheduled for their initial testing visit.

\subsection{Supplementation}

Subjects were randomly assigned in double-blind manner, using a cross-over design, to both the supplement and placebo. Each condition (one capsule) was ingested daily for a period of 14 days, with a 14-day washout period between assignments. The supplement contained the following ingredients per one capsule: $400 \mathrm{mg}$ of Spilanthes acmella extract and $25 \mathrm{mg}$ of Orchis latifolia extract. Both of these ingredients have been used in Ayurvedic medicine for many years and are believed to stimulate testosterone production. Spilanthes acmella has been reported to increase testosterone in animals (Sharma et al., 2011). A recent uncontrolled pilot study in humans who ingested Spilanthes acmella noted an increase in testosterone that was observed within 7 days of treatment (unpublished findings). Limited data are available with regard to Orchis latifolia, although a dose dependent effect regarding androgenic activity has been noted in animals treated with this agent (Bhargava et al., 2009). The placebo capsules contained cellulose. Both the supplement and placebo capsules were produced according to Good Manufacturing Practice (GMP). Capsules were similar in appearance and provided to subjects in unlabeled bottles. Subjects returned their capsule bottle after two weeks of intake to determine capsule compliance (via counting of remaining capsules).

\subsection{Test Visit Procedures}

For each condition (supplement and placebo), subjects reported to the lab a total of four times. These included the mornings (i.e. 6:00-8:00am) of days 1, 4, 8, and 15. The time of day was matched for each subject. Subjects reported to the lab in a 10-hour fasted state. They were instructed to abstain from strenuous activity, avoid consumption of alcohol, and not to engage in sexual activity within the 48 hours prior to testing. Subjects were also instructed to obtain at least 7 hours of sleep during the night prior to testing. No supplement or placebo capsules were taken on the morning prior to blood collection (with the exception of day 15-see explanation below).

On each day, following a 20-minute period of quiet rest, a blood sample was taken from subjects via venipuncture. On day 15 only (for both supplement and placebo), blood samples were collected from an indwelling venous catheter prior to ingestion of the supplement or placebo, as well as at 30,60,90,120,150, and 180 minutes post ingestion of two capsules of the assigned condition (supplement or placebo). This allowed for the determination of the acute effects of the supplement on circulating testosterone. No food or calorie containing beverages were allowed during this three-hour period.

Venous blood samples $(\sim 15 \mathrm{~mL})$ were taken from subjects via needle and Vacutainer ${ }^{\circledR}$ on days 
1,4 , and 8 , as indicated above. On day 15 , samples were collected via an indwelling venous catheter. Following collection, samples were processed accordingly and the plasma and serum was stored at $-70^{\circ} \mathrm{C}$ until analyzed. Samples analysis for total testosterone (catalogue: TE187S) and cortisol (catalogue: CO103S) was done using serum. Enzyme linked immunosorbent assay (ELISA) procedures were followed according to the instructions provided by the manufacturer (Calbiotech, Inc. Spring Valley, CA). Nitrate/nitrite was analyzed in plasma using a commercially available colorimetric assay kit (catalogue: 780001) according to the procedures provided by the manufacturer (Caymen Chemical, Ann Arbor, MI). Prior to analysis, all samples were mixed thoroughly following thawing. All samples were analyzed in duplicate and on first thaw. The coefficient of variation for the assays was as follows: total testosterone $4.4 \%$, cortisol $3.9 \%$; nitrate/nitrite $1.8 \%$.

\subsection{Questionnaire}

Due to the potential influence of circulating testosterone and NO on health-specific feelings, a questionnaire was completed by subjects on the morning of each test day. Using a scale of 1-10, with 1 representing the lowest rating and 10 representing the highest rating, subjects rated a number of variables pertaining to overall health with regards to how they felt over the past three days.

\subsection{Dietary Intake and Recording}

All subjects were instructed to consume their usual diet and to record dietary intake during the 24 hours prior to each day of testing. Dietary records were analyzed using nutritional software (Food Processor Pro; ESHA Research, Salem, OR).

\subsection{Statistical Analysis}

Data specific to chronic ingestion of the supplement and placebo were analyzed using a 2 (condition) by 4 (day) repeated measures analysis of variance (ANOVA). Data pertaining to the acute intake of the supplement and placebo were analyzed using a 2 (condition) x 7 (time) repeated measures ANOVA. The data are presented as mean \pm SEM. All analyses were performed using JMP statistical software. Statistical significance was set at $\mathrm{p} \leq 0.05$.

\section{Results}

A total of 13 subjects completed this study. However, on the first day of venous catheter placement, one subject fainted in response to the procedure. Therefore, we decided not to continue with venous catheter placement for this subject and data pertaining to acute intake of the supplement and placebo are not available for this subject (only a total of 12 subjects' data are available with regards to the acute intake portion of the study).

Compliance to capsule intake was excellent and not different between supplement $(99.5 \pm 0.5 \%)$ and placebo $(97.7 \pm 1.3 \%)(\mathrm{p}=0.19)$. Subjects appeared to be in good health and performed a significant volume of exercise training (Table 1). No statistically significant differences were noted for any variable related to dietary intake ( $>>0.05$; Table 2$)$ or subjects' perceived feelings associated with use of the supplement or placebo ( $>0.05$; Table 3 ). However, perceived energy and alertness was increased $8 \%$ and $13 \%$, respectively, from day 
1 to day 15 when subjects ingested the supplement.

Table 2. Dietary data of 13 men during the 24 hour period prior to each test day for supplement or placebo

\begin{tabular}{lcccccccc}
\hline Variable & Supplement & Supplement & Supplement & Supplement & Placebo & Placebo & Placebo & Placebo \\
& Day 1 & Day 4 & Day 8 & Day 15 & Day 1 & Day 4 & Day 8 & Day 15 \\
\hline Kcal & $2189 \pm 242$ & $2453 \pm 444$ & $3192 \pm 570$ & $2176 \pm 257$ & $2772 \pm 351$ & $2407 \pm 325$ & $2133 \pm 292$ & $2365 \pm 280$ \\
Protein (g) & $147 \pm 17$ & $150 \pm 21$ & $172 \pm 33$ & $127 \pm 17$ & $144 \pm 18$ & $126 \pm 15$ & $116 \pm 17$ & $146 \pm 15$ \\
Carbohydrate (g) & $258 \pm 46$ & $306 \pm 64$ & $346 \pm 53$ & $248 \pm 40$ & $298 \pm 49$ & $249 \pm 42$ & $244 \pm 40$ & $250 \pm 44$ \\
Fat (g) & $78 \pm 9$ & $80 \pm 15$ & $127 \pm 34$ & $80 \pm 12$ & $135 \pm 20$ & $108 \pm 15$ & $85 \pm 11$ & $96 \pm 9$ \\
Vitamin C (mg) & $51 \pm 17$ & $39 \pm 15$ & $67 \pm 24$ & $99 \pm 38$ & $57 \pm 25$ & $98 \pm 42$ & $78 \pm 33$ & $57 \pm 22$ \\
Vitamin E (mg) & $5 \pm 2$ & $4 \pm 1$ & $6 \pm 3$ & $4 \pm 2$ & $5 \pm 2$ & $7 \pm 3$ & $4 \pm 1$ & $6 \pm 2$ \\
Vitamin A (RE) & $919 \pm 321$ & $401 \pm 176$ & $574 \pm 201$ & $144 \pm 36$ & $1934 \pm 1497$ & $1997 \pm 1534$ & $1911 \pm 1577$ & $598 \pm 244$ \\
\hline
\end{tabular}

Data are mean \pm SEM.

No statistically significant differences noted $(\mathrm{p}>0.05)$.

Table 3. Subjective ratings of 13 men before and following ingestion of supplement or placebo

\begin{tabular}{lcccccccc}
\hline Variable & Supplement & Supplement & Supplement & Supplement & Placebo & Placebo & Placebo & Placebo \\
& Day 1 & Day 4 & Day 8 & Day 15 & Day 1 & Day 4 & Day 8 & Day 15 \\
\hline Alert & $6.7 \pm 0.5$ & $7.5 \pm 0.4$ & $7.5 \pm 0.5$ & $7.6 \pm 0.6$ & $7.6 \pm 0.4$ & $7.5 \pm 0.5$ & $7.3 \pm 0.5$ & $7.6 \pm 0.5$ \\
Energy & $7.2 \pm 0.5$ & $7.7 \pm 0.5$ & $7.2 \pm 0.5$ & $7.8 \pm 0.5$ & $7.6 \pm 0.5$ & $7.2 \pm 0.6$ & $7.1 \pm 0.6$ & $7.0 \pm 0.5$ \\
Aggressive & $4.9 \pm 0.8$ & $4.8 \pm 0.8$ & $4.9 \pm 0.8$ & $5.2 \pm 0.7$ & $5.5 \pm 0.8$ & $5.1 \pm 0.8$ & $5.0 \pm 0.8$ & $5.5 \pm 0.7$ \\
Vitality & $7.2 \pm 0.6$ & $7.4 \pm 0.6$ & $7.4 \pm 0.5$ & $7.5 \pm 0.5$ & $7.2 \pm 0.5$ & $7.3 \pm 0.4$ & $7.2 \pm 0.5$ & $7.3 \pm 0.5$ \\
Libido & $6.2 \pm 0.7$ & $7.0 \pm 0.7$ & $6.7 \pm 0.6$ & $6.5 \pm 0.7$ & $6.4 \pm 0.6$ & $6.3 \pm 0.6$ & $6.8 \pm 0.7$ & $6.8 \pm 0.7$ \\
Sleep & $6.0 \pm 0.6$ & $6.9 \pm 0.5$ & $6.5 \pm 0.4$ & $6.5 \pm 0.7$ & $6.5 \pm 0.6$ & $6.8 \pm 0.5$ & $7.2 \pm 0.5$ & $7.0 \pm 0.4$ \\
Mental Outlook & $7.5 \pm 0.5$ & $7.9 \pm 0.5$ & $7.9 \pm 0.4$ & $7.5 \pm 0.5$ & $7.8 \pm 0.4$ & $7.7 \pm 0.4$ & $7.8 \pm 0.5$ & $7.5 \pm 0.6$ \\
Appearance & $7.2 \pm 0.4$ & $7.2 \pm 0.5$ & $7.5 \pm 0.5$ & $7.3 \pm 0.5$ & $7.3 \pm 0.4$ & $7.2 \pm 0.4$ & $7.4 \pm 0.5$ & $7.2 \pm 0.5$ \\
Strength & $7.2 \pm 0.4$ & $7.6 \pm 0.4$ & $7.2 \pm 0.5$ & $7.5 \pm 0.5$ & $6.8 \pm 0.6$ & $7.0 \pm 0.5$ & $7.3 \pm 0.5$ & $7.2 \pm 0.5$ \\
Endurance & $7.0 \pm 0.5$ & $7.5 \pm 0.6$ & $7.1 \pm 0.6$ & $7.3 \pm 0.6$ & $7.0 \pm 0.6$ & $7.0 \pm 0.5$ & $7.5 \pm 0.5$ & $7.4 \pm 0.7$ \\
\hline
\end{tabular}

Data are mean \pm SEM.

No statistically significant differences noted ( $p>0.05)$.

With regards to the biochemical variables, no changes of statistical significance were noted (p>0.05; Table 4). Of the 13 men who were tested, 8 were noted to be "responders" to treatment when considering the change in testosterone from day 1 to day 15 . When using the entire sample of 13 men, the mean percent increase from day 1 to day 15 was $29 \%$ for supplement and $6 \%$ for the placebo. When including only those 8 subjects noted to be 
responders to treatment, the mean percent increase from day 1 to day 15 was $56 \%$ for the supplement and $4 \%$ for the placebo. Individual subject data are shown in Figure 1. During the same time period (day 1 to day 15), cortisol was $19 \%$ higher when subjects ingested the supplement versus $9 \%$ higher when subjects ingested the placebo. Nitrate/nitrate was very stable across time for both supplement and placebo. Acute treatment with a double dose of the supplement or placebo did not impact testosterone values ( $p>0.05$; Table 5).

Table 4. Biochemical data of 13 men before and following ingestion of supplement or placebo

\begin{tabular}{lcccccccc}
\hline Variable & $\begin{array}{c}\text { Supplement } \\
\text { Day 1 }\end{array}$ & $\begin{array}{c}\text { Supplement } \\
\text { Day 4 }\end{array}$ & $\begin{array}{c}\text { Supplement } \\
\text { Day 8 }\end{array}$ & $\begin{array}{c}\text { Supplement } \\
\text { Day 15 }\end{array}$ & $\begin{array}{c}\text { Placebo } \\
\text { Day 1 }\end{array}$ & $\begin{array}{c}\text { Placebo } \\
\text { Day 4 }\end{array}$ & $\begin{array}{c}\text { Placebo } \\
\text { Day 8 }\end{array}$ & $\begin{array}{c}\text { Placebo } \\
\text { Day 15 }\end{array}$ \\
\hline $\begin{array}{l}\text { Testosterone } \\
\left(\mathrm{ng} \cdot \mathrm{mL}^{-1}\right)\end{array}$ & $4.9 \pm 1.1$ & $5.9 \pm 1.3$ & $5.8 \pm 1.3$ & $6.4 \pm 1.5$ & $6.0 \pm 1.5$ & $6.1 \pm 1.5$ & $6.0 \pm 1.4$ & $6.4 \pm 1.5$ \\
$\begin{array}{l}\text { Cortisol } \\
\left(\mathrm{ng} \cdot \mathrm{mL}^{-1}\right)\end{array}$ & $276.0 \pm 40.8$ & $309.8 \pm 43.8$ & $294.6 \pm 39.2$ & $329.7 \pm 50.0$ & $286.9 \pm 37.8$ & $270.7 \pm 32.7$ & $296.5 \pm 41.9$ & $313.5 \pm 50.6$ \\
$\begin{array}{l}\text { Nitrate/Nitrite } \\
\left(\mu \mathrm{mol} \cdot \mathrm{L}^{-1}\right)\end{array}$ & $27.9 \pm 2.9$ & $30.9 \pm 3.4$ & $30.3 \pm 3.1$ & $26.4 \pm 2.7$ & $32.9 \pm 5.2$ & $31.2 \pm 7.4$ & $32.5 \pm 8.3$ & $29.8 \pm 5.6$ \\
\hline
\end{tabular}

Data are mean \pm SEM.

No statistically significant differences noted ( $p>0.05)$.

Table 5. Testosterone data (ng.mL-1) of 13 men before and following acute ingestion of supplement or placebo

Data are mean \pm SEM.

\begin{tabular}{lcc}
\hline Time & Supplement & Placebo \\
\hline Pre & $6.4 \pm 1.5$ & $6.4 \pm 1.5$ \\
$30 \mathrm{~min}$ & $6.2 \pm 1.6$ & $6.1 \pm 1.5$ \\
$60 \mathrm{~min}$ & $6.2 \pm 1.5$ & $5.2 \pm 1.2$ \\
$90 \mathrm{~min}$ & $6.1 \pm 1.6$ & $6.1 \pm 1.5$ \\
$120 \mathrm{~min}$ & $5.4 \pm 1.3$ & $6.5 \pm 1.5$ \\
$150 \mathrm{~min}$ & $6.4 \pm 1.6$ & $6.5 \pm 1.6$ \\
$180 \mathrm{~min}$ & $6.5 \pm 1.6$ & $6.5 \pm 1.5$ \\
\hline
\end{tabular}

No statistically significant differences noted $(\mathrm{p}>0.05)$.

\section{Discussion}

Data from the present investigation indicate that two weeks of supplementation with an herbal preparation containing Spilanthes acmella extract and Orchis latifolia extract can increase circulating testosterone in selected young men. As with most dietary supplements, some individuals appear to be responders to treatment, while others are not. Since this study included a small number of healthy young men supplemented for only a two-week period, additional studies are needed to determine the impact of this supplement on testosterone using a much larger sample of men, ideally following a longer-term period of treatment. 
With regards to testosterone and associated variables, prior animal studies involving Spilanthes acmella have noted dose dependent increases in serum testosterone. For example, Splianthes acmella extracts have been shown to affect the general mating pattern, penile erection and serum homone levels in normal male Wistar albino rats (Sharma et al., 2011). In this instance, Spilanthes acmella extracts were administered at 50, 100 and $150 \mathrm{mg} / \mathrm{kg}$ body weight per day for 28 days, using sildenafil citrate as a positive control ( $5 \mathrm{mg} / \mathrm{kg}$ body weight) (Sharma et al., 2011). The extract had a dose dependent effect on testosterone serum levels, mounting frequency, intromission frequency and ejaculation frequency (Sharma et al., 2011). One theory pertaining to the aphrodisiac potential of Spilanthes acmella is the natural presence of $N$-alkylamides in the extract (Sharma et al., 2011).

While the above has been reported pertaining to Spilanthes acmella, data specific to Orchis latifolia and testosterone has also shown dose dependent effects. An evaluation on the effects of Orchis latifolia in male albino rats notes a significant increase in serum testosterone post treatment (Bhargava et al., 2009). The greatest effects were observed at a dose of $200 \mathrm{mg} / \mathrm{kg}$ body weight, providing concomitant increases in body mass, reproductive organ mass, and sexual behavior (Bhargava et al., 2009). Interestingly, improvements to spermatogenesis were also noted via histological examination of the testicular tissues (Bhargava et al., 2009).

With regards to NO, data are scarce as pertaining to the use of either Spilanthes acmella or Orchis latifolia to increase this molecule or associated variables (e.g., blood flow). In vitro experiments examining nitric oxide in human corpus cavernosum cell lines show significant increases in NO release when exposed to Spilanthes acmella extract (10 mg/ml) compared to controls $(21.7 \pm 2.9 \mu \mathrm{M}$ and $8.83 \pm 0.98 \mu \mathrm{M}$, respectively) (Sharma et al., 2011). Along the same lines, previous data indicates that Orchis latifolia increases NO levels in rats treated at a dose of $200 \mathrm{mg} / \mathrm{kg}$ of body weight (Bhargava et al., 2009). Contrary to these data, our results showed no significant increase in NO metabolites in subjects taking the botanical supplement versus placebo. It is possible that the relative small dose of the botanical could be responsible for our noted lack of increase.

As can be viewed in Table 4, we failed to note any changes of statistical significance for any measured biochemical variable. Nitrate/nitrite was nearly unchanged across time for either supplement or placebo, while both cortisol and testosterone increased over time with ingestion of the supplement. As indicated in the Results section of this paper, 8 of the 13 men responded to supplementation and experienced an increase in testosterone from day 1 to day 15 of $56 \%$. While this is a sizable increase, it was attributed primarily to 4 of the 8 subjects (see Figure 1). Future studies are needed to determine the magnitude of testosterone elevation in a larger sample of subjects. Moreover, since cortisol was elevated to a slightly greater extent from day 1 to day 15 following treatment with the supplement (19\%) as compared to the placebo (9\%), future work is needed to determine if any significant increase in testosterone is paralleled by a concomitant increase in cortisol.

With regards to the acute intake of the supplement on circulating testosterone, we failed to note any increase in testosterone following a single ingestion of the supplement (Table 5). Therefore, it appears that routine ingestion of the ingredients is needed to experience any 


\section{Ml Macrothink}

increase in testosterone.

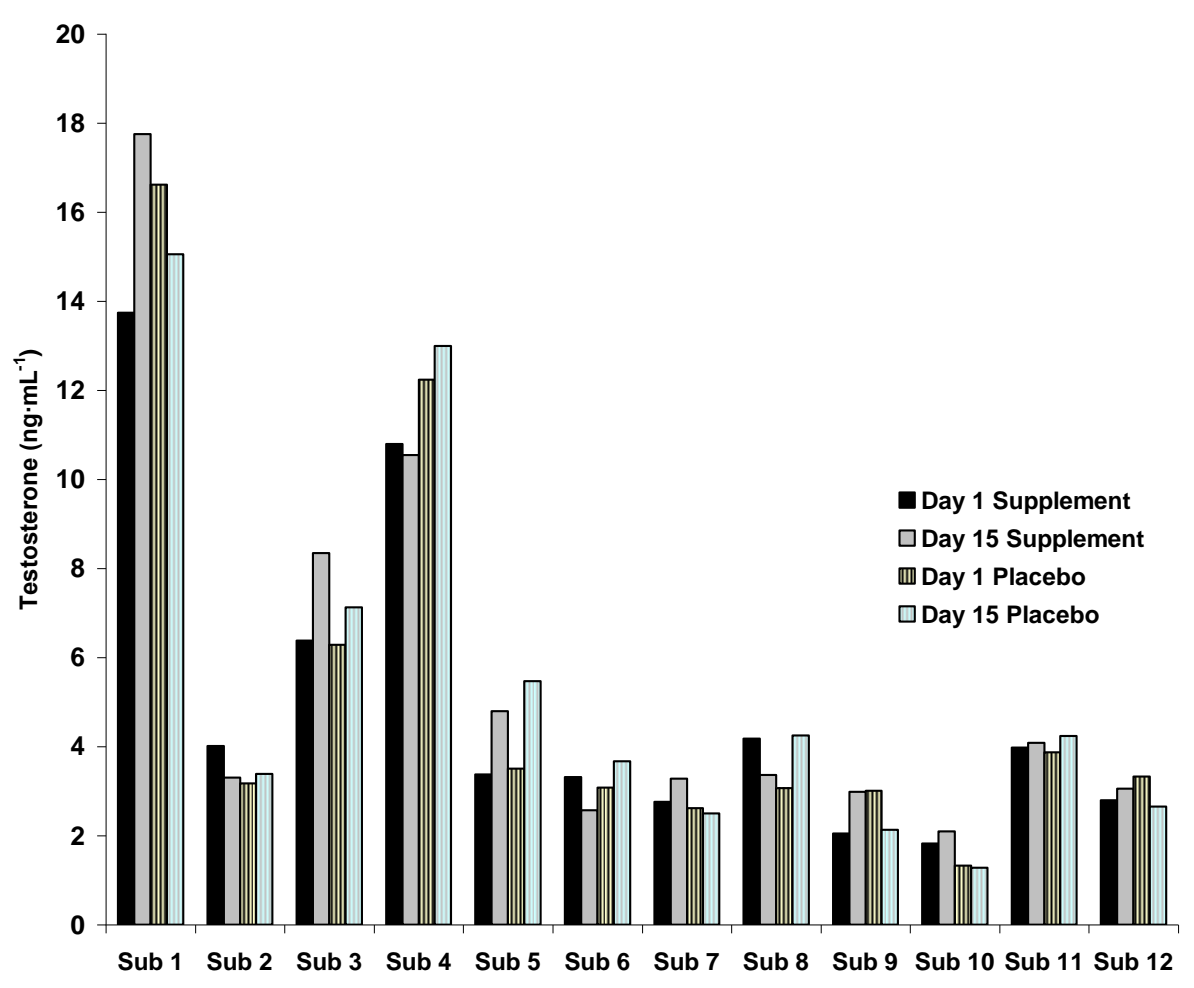

Figure 1. Individual testosterone data $\left(\mathrm{ng} \cdot \mathrm{mL}^{-1}\right)$ of 12 men before and following ingestion of supplement or placebo for 14 days

Note: Day 1 Supplement data missing for one subject (data not shown for this subject).

While not a main focal point of this investigation, we measured subjects' subjective feelings of energy, alertness, and associated variables. While not of statistical significance, we noted an increase of $8 \%$ and $13 \%$ for energy and alertness, respectively, from day 1 to day 15 when subjects ingested the supplement. No increase in these measures was noted for subjects when ingesting the placebo. Any future work may further investigate the subjective measures associated with elevated testosterone and NO.

In conclusion, we report for the first time that a dietary supplement containing Spilanthes acmella extract and Orchis latifolia extract can increase circulating testosterone in selected healthy men; however, not all men respond to treatment with the supplement. Moreover, serum cortisol is elevated to a greater extent with the supplement as compared to with the placebo. Additional studies inclusive of a much larger sample size are needed to further evaluate the impact of this herbal combination on testosterone in men.

\section{Acknowledgements}

Funding for this work was provided in part by Research Development Innovations, LLC and The University of Memphis. Appreciation is extended to Matt Butawan for assistance with manuscript preparation. 


\section{Conflict of interest}

RJ Bloomer has been a principal investigator on research projects and a consultant to dietary ingredient and supplement companies. No other author declares any conflict of interest.

\section{Authors' contributions}

RGM was responsible for management of the study protocol, data collection and entry, and assistance with manuscript preparation. ATV assisted with data collection and manuscript preparation. RJB was responsible for the study design, biochemical analyses, statistical analyses, and manuscript preparation. All authors read and approved of the final manuscript.

\section{References}

Achike, F. I., \& Kwan, C. (2003). Nitric oxide, human diseases and the herbal products that affect the nitric oxide signalling pathway. Clinical and Experimental Pharmacology and Physiology, 30(9), 605-615. http://dx.doi.org/10.1210/jcem-47-2-268

Amatruda, J. M., Harman, S. M., Pourmotabbed, G., \& Lockwoodf, D. H. (1978). Depressed plasma testosterone and fractional binding of testosterone in obese males. The Journal of Clinical Endocrinology \& Metabolism, 47(2), 268-271.

Andersen, M. L., Martins, P. J., D'AlMEIDA, V., Bignotto, M., \& Tufik, S. (2005). Endocrinological and catecholaminergic alterations during sleep deprivation and recovery in male rats. Journal of Sleep Research, 14(1), 83-90. http://dx.doi.org/10.1111/j.1365-2869.2004.00428.x

Andersen, M. L., \& Tufik, S. (2008). The effects of testosterone on sleep and sleep-disordered breathing in men: Its bidirectional interaction with erectile function. Sleep Medicine Reviews, 12(5), 365-379. http://dx.doi.org/10.1016/j.smrv.2007.12.003

Anderson, K. E., Rosner, W., Khan, M., New, M. I., Pang, S., Wissel, P. S., \& Kappas, A. (1987). Diet-hormone interactions: Protein/carbohydrate ratio alters reciprocally the plasma levels of testosterone and cortisol and their respective binding globulins in man. Life Sciences, 40(18), 1761-1768. http://dx.doi.org/10.1016/0024-3205(87)90086-5

Arazi, H., Damirchi, A., Faraji, H., \& Rahimi, R. (2012). Hormonal responses to acute and chronic resistance exercise in middle-age versus young men. Sport Sciences for Health, 8(2-3), 59-65. http://dx.doi.org/10.1007/s11332-012-0131-8

Bhargava, C. S., Thakur, M., Patil, U. K., \& Dixit, V. K. (2009). Evaluation of androgenic and aphrodisiac activity of orchis latifolia L. in male albino rats. Zeitschrift Für Phytotherapie, 30(S 01), P04.

Bode-Boger, S. M., Boger, R. H., Schroder, E. P., \& Frolich, J. C. (1994). Exercise increases systemic nitric oxide production in men. Journal of Cardiovascular Risk, 1(2), 173-178. http://dx.doi.org/10.1177/174182679400100212

Bond, H., Morton, L., \& Braakhuis, A. J. (2012). Dietary nitrate supplementation improves rowing performance in well-trained rowers. 
Bulpitt, C. J., Li, Y., Bulpitt, P. F., \& Wang, J. (2007). The use of orchids in chinese medicine. Journal of the Royal Society of Medicine, 100(12), 558-563. http://dx.doi.org/10.1258/jrsm.100.12.558

Carnahan, R. M., \& Perry, P. J. (2004). Depression in aging men. Drugs \& Aging, 21(6), 361-376. http://dx.doi.org/10.2165/00002512-200421060-00002

Clements, W. T., Lee, S., \& Bloomer, R. J. (2014). Nitrate ingestion: A review of the health and physical performance effects. Nutrients, 6(11), 5224-5264. http://dx.doi.org/10.3390/nu6115224

Cortes-Gallegos, V., Castaneda, G., Alonso, R., Sojo, I., Carranco, A., Cervantes, C., \& Parra, A. (1983). Sleep deprivation reduces circulating androgens in healthy men. Archives of Andrology, 10(1), 33-37. http://dx.doi.org/10.3109/01485018308990167

Crecelius, A. R., Kirby, B. S., Voyles, W. F., \& Dinenno, F. A. (2011). Augmented skeletal muscle hyperaemia during hypoxic exercise in humans is blunted by combined inhibition of nitric oxide and vasodilating prostaglandins. The Journal of Physiology, 589(14), 3671-3683. http://dx.doi.org/10.1113/jphysiol.2011.209486

Doering, C. H., Brodie, K. H., Kraemer, H. C., Moos, R. H., Becker, H. B., \& Hamburg, D. A. (1975). Negative affect and plasma testosterone: A longitudinal human study. Psychosomatic Medicine, 37(6), 484-491. http://dx.doi.org/10.1097/00006842-197511000-00003

Dubey, S., Maity, S., Singh, M., Saraf, S. A., \& Saha, S. (2013). Phytochemistry, pharmacology and toxicology of spilanthes acmella: A review. Advances in Pharmacological Sciences, 2013, 423750. http://dx.doi.org/10.1155/2013/423750

Egan, B., Hodgkins, C., Shepherd, R., Timotijevic, L., \& Raats, M. (2011). An overview of consumer attitudes and beliefs about plant food supplements. Food \& Function, 2(12), 747-752. http://dx.doi.org/10.1039/c1fo10109a

Gunnels, T. A., \& Bloomer, R. J. (2014). Increasing circulating testosterone: Impact of herbal dietary supplements. Journal of Plant Biochemistry \& Physiology, 2014

Hsieh, T. C., Juan, G., Darzynkiewicz, Z., \& Wu, J. M. (1999). Resveratrol increases nitric oxide synthase, induces accumulation of p53 and p21(WAF1/CIP1), and suppresses cultured bovine pulmonary artery endothelial cell proliferation by perturbing progression through $\mathrm{S}$ and G2. Cancer Research, 59(11), 2596-2601.

Kellogg, D. L.,Jr, Crandall, C. G., Liu, Y., Charkoudian, N., \& Johnson, J. M. (1998). Nitric oxide and cutaneous active vasodilation during heat stress in humans. Journal of Applied Physiology (Bethesda, Md.: 1985), 85(3), 824-829.

Kelly, J., Vanhatalo, A., Wilkerson, D. P., Wylie, L. J., \& Jones, A. M. (2013). Effects of nitrate on the power-duration relationship for severe-intensity exercise. Med Sci Sports Exerc, 45(9), 1798-1806. http://dx.doi.org/10.1249/MSS.0b013e31828e885c 
Koller, A., Huang, A., Sun, D., \& Kaley, G. (1995). Exercise training augments flow-dependent dilation in rat skeletal muscle arterioles. role of endothelial nitric oxide and $\begin{array}{llll}\text { prostaglandins. } & \text { Circulation } & \text { Research, } & \text { 76(4), }\end{array}$ http://dx.doi.org/10.1161/01.RES.76.4.544

Kraemer, W. J., Fry, A. C., Warren, B. J., Stone, M. H., Fleck, S. J., Kearney, J. T., . . . Triplett, N. T. (1992). Acute hormonal responses in elite junior weightlifters. International Journal of Sports Medicine, 13(2), 103-109. http://dx.doi.org/10.1055/s-2007-1021240

Laaksonen, D. E., Niskanen, L., Punnonen, K., Nyyssonen, K., Tuomainen, T. P., Valkonen, V. P., . . Salonen, J. T. (2004). Testosterone and sex hormone-binding globulin predict the metabolic syndrome and diabetes in middle-aged men. Diabetes Care, 27(5), 1036-1041. http://dx.doi.org/10.2337/diacare.27.5.1036

Laughlin, G. A., Barrett-Connor, E., \& Bergstrom, J. (2008). Low serum testosterone and mortality in older men. The Journal of Clinical Endocrinology \& Metabolism, 93(1), 68-75. http://dx.doi.org/10.1210/jc.2007-1792

Lima, A., Ritti-Dias, R., Forjaz, C. L., Correia, M., Miranda, A., Brasileiro-Santos, M., . . . Silva, A. (2014). A session of resistance exercise increases vasodilation in intermittent claudication patients. Applied Physiology, Nutrition, and Metabolism, 40(1), 59-64. http://dx.doi.org/10.1139/apnm-2014-0342

Linnamo, V., Pakarinen, A., Komi, P. V., Kraemer, W. J., \& Hakkinen, K. (2005). Acute hormonal responses to submaximal and maximal heavy resistance and explosive exercises in men and women. Journal of Strength and Conditioning Research / National Strength \& Conditioning Association, 19(3), 566-571. http://dx.doi.org/10.1519/R-15404.1

Markianos, M., Tripodianakis, J., Sarantidis, D., \& Hatzimanolis, J. (2007). Plasma testosterone and dehydroepiandrosterone sulfate in male and female patients with dysthymic disorder. Journal of Affective Disorders, 101(1), 255-258. http://dx.doi.org/10.1016/j.jad.2006.11.013

Medina-Remón, A., Tresserra-Rimbau, A., Pons, A., Tur, J. A., Martorell, M., Ros, E., . . . Corella, D. (2015). Effects of total dietary polyphenols on plasma nitric oxide and blood pressure in a high cardiovascular risk cohort. the PREDIMED randomized trial. Nutrition, Metabolism and Cardiovascular Diseases, 25(1), 60-67. http://dx.doi.org/10.1016/j.numecd.2014.09.001

Ng Tang Fui, M., Hoermann, R., Cheung, A., Gianatti, E., Zajac, J., \& Grossmann, M. (2013). Obesity and age as dominant correlates of low testosterone in men irrespective of diabetes status. Andrology, 1(6), 906-912. http://dx.doi.org/10.1111/j.2047-2927.2013.00124.x

Nicklas, B. J., Ryan, A. J., Treuth, M. M., Harman, S. M., Blackman, M. R., Hurley, B. F., \& Rogers, M. A. (1995). Testosterone, growth hormone and IGF-I responses to acute and chronic resistive exercise in men aged 55-70 years. International Journal of Sports Medicine, 16(7), 445-450. http://dx.doi.org/10.1055/s-2007-973035 
Nicoletti, M. (2012). Nutraceuticals and botanicals: Overview and perspectives. International Journal of Food Sciences and Nutrition, 63(sup1), 2-6. http://dx.doi.org/10.3109/09637486.2011.628012

Raskin, I., Ribnicky, D. M., Komarnytsky, S., Ilic, N., Poulev, A., Borisjuk, N., . . Yakoby, N. (2002). Plants and human health in the twenty-first century. Trends in Biotechnology, 20(12), 522-531. http://dx.doi.org/10.1016/S0167-7799(02)02080-2

Reed, M., Cheng, R., Simmonds, M., Richmond, W., \& James, V. (1987). Dietary lipids: An additional regulator of plasma levels of sex hormone binding globulin. The Journal of Clinical Endocrinology \& Metabolism, 64(5), 1083-1085. http://dx.doi.org/10.1210/jcem-64-5-1083

Schneider, G., Kirschner, M. A., Berkowitz, R., \& Ertel, N. H. (1979). Increased estrogen production in obese men*. The Journal of Clinical Endocrinology \& Metabolism, 48(4), 633-638. http://dx.doi.org/10.1210/jcem-48-4-633

Seidman, S. N., Araujo, A. B., Roose, S. P., Devanand, D., Xie, S., Cooper, T. B., \& McKinlay, J. B. (2002). Low testosterone levels in elderly men with dysthymic disorder. American Journal of Psychiatry,

Sharma, V., Boonen, J., Chauhan, N. S., Thakur, M., De Spiegeleer, B., \& Dixit, V. K. (2011). Spilanthes acmella ethanolic flower extract: LC-MS alkylamide profiling and its effects on sexual behavior in male rats. Phytomedicine, 18(13), 1161-1169. http://dx.doi.org/10.1016/j.phymed.2011.06.001

Shores, M. M., Matsumoto, A. M., Sloan, K. L., \& Kivlahan, D. R. (2006). Low serum testosterone and mortality in male veterans. Archives of Internal Medicine, 166(15), 1660-1665. http://dx.doi.org/10.1001/archinte.166.15.1660

Srinivas-Shankar, U., Roberts, S. A., Connolly, M. J., O'Connell, M. D., Adams, J. E., Oldham, J. A., \& Wu, F. C. (2010). Effects of testosterone on muscle strength, physical function, body composition, and quality of life in intermediate-frail and frail elderly men: A randomized, double-blind, placebo-controlled study. The Journal of Clinical Endocrinology \& Metabolism, 95(2), 639-650. http://dx.doi.org/10.1210/jc.2009-1251

Tanaka, L. Y., Bechara, L. R. G., dos Santos, A. M., Jordão, C. P., de Sousa, Luís Gustavo Oliveira, Bartholomeu, T., . . Ramires, P. R. (2015). Exercise improves endothelial function: A local analysis of production of nitric oxide and reactive oxygen species. Nitric Oxide, 45, 7-14. http://dx.doi.org/10.1016/j.niox.2015.01.003

Thakur, M., \& Dixit, V. K. (2008). Ameliorative effect of fructo-oligosaccharide rich extract of orchis latifolia linn. on sexual dysfunction in hyperglycemic male rats. Sexuality and Disability, 26(1), 37-46.

Travison, T. G., Araujo, A. B., Kupelian, V., O’Donnell, A. B., \& McKinlay, J. B. (2007). The relative contributions of aging, health, and lifestyle factors to serum testosterone decline 


\section{Macrothink}

in men. The Journal of Clinical Endocrinology \& Metabolism, 92(2), 549-555. http://dx.doi.org/10.1210/jc.2006-1859

Tsujimura, A. (2013). The relationship between testosterone deficiency and men's health. The World Journal of Men's Health, 31(2), 126-135. http://dx.doi.org/10.5534/wjmh.2013.31.2.126

White, J. W. (1975). Relative significance of dietary sources of nitrate and nitrite. Journal of Agricultural and Food Chemistry, 23(5), 886-891. http://dx.doi.org/10.1021/jf60201a034

Wongsawatkul, O., Prachayasittikul, S., Isarankura-Na-Ayudhya, C., Satayavivad, J., Ruchirawat, S., \& Prachayasittikul, V. (2008). Vasorelaxant and antioxidant activities of spilanthes acmella murr. International Journal of Molecular Sciences, 9(12), 2724-2744. http://dx.doi.org/10.3390/ijms9122724

Zand, J., Lanza, F., Garg, H. K., \& Bryan, N. S. (2011). All-natural nitrite and nitrate containing dietary supplement promotes nitric oxide production and reduces triglycerides in humans. Nutrition Research, 31(4), 262-269. http://dx.doi.org/10.1016/j.nutres.2011.03.008

\section{Copyright Disclaimer}

Copyright for this article is retained by the author(s), with first publication rights granted to the journal.

This is an open-access article distributed under the terms and conditions of the Creative Commons Attribution license (http://creativecommons.org/licenses/by/3.0/). 